\title{
Coronary ostial stenosis and aortic aneurysm caused by syphilis
}

\author{
Fergus To MD, Omid Kiamanesh MD
}

Cite as: CMAJ 2017 March 6;189:E369. doi: 10.1503/cmaj.151133

A 58-year-old man presented to the emergency department with a two-week history of crescendo angina. Initial physical examination, biomarkers and an electrocardiogram (ECG) were unremarkable. While walking in the emergency department, the patient collapsed and went into cardiogenic shock. An ECG showed anterior ST-segment depression and new intraventricular conduction delay. Emergency angiography showed $90 \%$ ostial stenosis of the left main coronary artery that was suggestive of a thrombus or dissection flap. The ascending aorta was dilated (4.3 cm in diameter). Computed tomography angiography showed para-aortic circumferential soft-tissue attenuation consistent with aortitis (Figure $1 \mathrm{~A}$ ).

The patient underwent emergent replacement of the ascending aorta arch and bypass of the left anterior descending and circumflex coronary arteries. Results from histopathologic analysis were consistent with acute inflammatory necrotizing aortitis. There was plasma cell infiltrate of the medial and adventitial vasa vasorum, and endarteritis obliterans of the vasa vasorum. Serologic screening for syphilis showed a reactive rapid plasma reagin test (titer 1:64) and a positive result for Treponema pallidum passive particle agglutination assay. Microscopic examination using a silver impregnation technique showed numerous spirochetes consistent with T. pallidum, which confirmed cardiovascular syphilis (Figure 1B). Our patient was given 18 million units of continuous penicillin $\mathrm{G}$ infusion for 10 days. At one-year follow-up, the patient had no symptoms.

Cardiovascular syphilis is a late complication of untreated tertiary syphilis that affects $12.8 \%$ of patients after an average disease duration of 30 years. ${ }^{1}$ Seventy-five percent of cases are complicated by aortic insufficiency, aortic aneurysm and/or coronary ostial stenosis. ${ }^{1}$ Syphilis serology test results may be negative because rapid plasma reagin titers decrease over time., ${ }^{2,3}$

Classic histopathology includes a "tree bark" appearance of the aortic intima, inflammatory infiltrate of the medial and adventitial vasa vasorum, and endarteritis obliterans of the vasa vasorum. ${ }^{4}$
Spirochetes in aortic tissue are seldom seen even with silver staining. ${ }^{4}$ All of these findings may not be present.

Benzathine penicillin $\mathrm{G}$ is used to treat cardiogenic syphilis. ${ }^{2}$ Clinicians should rule out central nervous system involvement and HIV co-infection. . $^{2,5}$

\section{References}

1. Clark EG, Danbolt N. The Oslo study of the natural history of untreated syphilis: an epidemiologic investigation based on a restudy of the Boeck-Bruusgaard material a review and appraisal. J Chronic Dis 1955;2:311-44.

2. Canadian guidelines on sexually transmitted infections. Ottawa: Public Health Agency of Canada; 2013. Available: www.phac-aspc.gc.ca/std-mts/sti-its/cgstiIdcits/section-5-10-eng.php (accessed 2015 July 15).

3. Ratnam S. The laboratory diagnosis of syphilis. Can J Infect Dis Med Microbiol 2005;16:45-51.

4. Gornik HL, Creager MA. Aortitis. Circulation 2008;117:3039-51.

5. Workowski KA, Bolan GA; Centers for Disease Control and Prevention. Sexually transmitted diseases treatment guidelines, 2015. MMWR Recomm Rep 2015;64:1-137.

\section{Competing interests: None declared.}

This article has been peer reviewed.

The authors have obtained patient consent.

Affiliation: Department of Medicine, Faculty of Medicine, The University of British Columbia, Vancouver, BC

Acknowledgements: The authors thank Dr. John English and Dr. Mohammed Mohammed for their contributions to this article.

Correspondence to: Fergus To, fergusto@alumni.ubc.ca 